\title{
Effect of Age on Immediate Postoperative Tissue Reaction Following Surgical Extraction of Impacted Mandibular Third Molar
}

\author{
Chandan Kumer Paul ${ }^{1}$, Quazi Billur Rahman², Shamiul Alam³, Gokul Chand Kundu, Helal Uzzaman ${ }^{5}$ \\ ${ }^{1}$ Indoor Medical Officer, Oral \& Maxillofacial Surgery Department, Dhaka Dental College Hospital, ${ }^{2}$ Professor \& Chairman, ${ }^{3}$ Assistant Professor, \\ ${ }^{4}$ Medical Officer, Department of Oral \& Maxillofacial Surgery, Bangabandhu Sheikh Mujib Medical University, Dhaka, Bangladesh, ${ }^{5}$ Registrar, Oral \\ \& Maxillofacial Surgery Department, Dhaka Dental College \& Hospital, Dhaka.
}

\begin{abstract}
:
Background: Postoperative morbidity following third molar surgery is affected by a number of factors.The aim of this study was to determine the effect of age on immediate postoperative tissue reactions following mandibular impacted third molar surgery. Objectives: To assess the discomforts after impacted mandibular third molar extraction in different aged patient. Methods : 100 patients, 54 Female and 46 Male,aged 18 to 42 years comprised the study materials. Tooth extraction was performed with buccal guttering technique after adequate elevation and reflection of full thickness mucoperiosteal flap. Pain, swelling and trismus were evaluated preoperatively and on 2nd POD and 7th POD. Data was processed and analyzed using SPSS and was compiled and test of significance was done using Chi square $\left(\mathrm{x}^{2}\right)$ test and unpaired ' $\mathrm{t}$ ' test. Results: Statistical analysis of the data indicated that pain and swelling was significantly less and significant maximum mouth opening was achieved in early aged patient than late age when preoperative and postoperative results were compared. Conclusion: As postoperative immediate tissue reactions are more in late aged patient than younger so impacted mandibular third molar should extract in early age.
\end{abstract}

Key Words: Impacted third Molar, Surgical Extraction,Postoperative tissue reaction.

[BSMMU J $2014 ; 7$ (2) : 120-128]

\section{Introduction :}

The third molar considered impacted when it is not fully erupted to the assumed normal functional position in the occlusal plane. Although a tooth may occasionally remain unerupted because of factors other than impaction ${ }^{1}$.The angulation of impaction of mandibular third molar was determined by the angle formed between the intersected longitudinal axes of the second and third molars. Vertical impaction:100 to-100, Mesioangular impaction :110 to 790 , Horizontal impaction: 800 to 1000 , Distoangular impaction:-110 to-790 and others:1110 to-80012. Relative depth of the third molar in bone was considered in relation to bone and the cervical line of second molar teeth. Position A: The highest portion of the tooth on a

Address for Correspondence: Chandan Kumer Paul, Indoor Medical Officer, Oral \& Maxillofacial Surgery Department, Dhaka Dental College Hospita . level with or above the occlusal line, Position B: The highest portion of the tooth below the occlusal line, but above the cervical line of the second molar, Position C: The highest portion of the tooth on the level with or below the cervical line of the second molar ${ }^{2}$.

The surgical removal of impacted mandibular third molar is the most frequent procedures in oral and maxillofacial surgery and can cause some postoperative pain, swelling, and trismus ${ }^{3}$. Moreover removal of impacted mandibular third molar is so common that the population morbidity of minor complications may be significant ${ }^{4}$. Age of the patients, type of impaction and duration of operation have been mentioned in scientific literatures as factors that influence the immediate postoperative reactions following third molar surgery but objective assessment are lacking. It was observe that the controversy surrounding 
third molars has focused on the pathologic problems they may cause and the risk / benefits of their removal ${ }^{5}$. This study aims to determine the effect of age on pain, swelling, and rismus following mandibular third molar surgeries.

The patient's age when the mandibular molar is removed has been reported to be of importance, and many studies have related postoperative complications to older age. The patient's age was found to be a risk indicator for an extended operation time. The older age groups had more than two times higher risk of an extended operation time compared with youngest age group. Older age was found to increase the risk of an extended operation time ${ }^{6}$. It was observed for every minute increase in operating time there was a $9 \%$ increase in chance of experiencing pain $(\mathrm{VAS}>1)^{7}$.

Patient's age was found to be a risk factor only for severe trismus; that is, patient's age $<22.0$ years were found to have a lower risk than older patients. Older patients are at greater risk of severe trismus after third molar surgery ${ }^{4}$.The surrounding bone in young patients is relatively soft and more resilient compare to older patient. As a result the patient's above 35 years were recorded more swelling and trismus ${ }^{8}$. Age is commonly cited as a risk factor for post extraction complications and age was found to be significantly associated with complications. In addition to change in bone density, increased age is associated with complete root formation and diminished wound healing capacities, which can result in higher operative and inflammatory complications ${ }^{9}$. Subjects over age 25 would be statistically significantly more likely to experience complications after third molar surgery compared with those under age $25^{10}$. Female and adult patients (age $>25$ years) should be informed before third molar surgery about the likelihood of requiring more time for improvements in oral function, lifestyle, and pain recovery compared with male and younger patients (age $<21$ years) following third molar surgery. It was observe that with increasing age and BMI the total time for extraction increased ${ }^{11}$. The amount of facial swelling varied depending on age and $\operatorname{sex}^{12}$.

There are significantly more females $(56 \%)$ than males (44\%) with at least one impacted third molar. The proportion of impacted mandibular third molars was significantly more than that of impacted maxillary third molar. Impacted third molars were 3.2 times more likely to occur in the mandible than in the maxilla. Mesioangularimpaction $(60 \%)$ and level B impaction $(80 \%)$ was the most common $^{13}$.

The most frequent immediate and late complications were pain, swelling, and trismus ${ }^{13}$.The longer the duration of tissue injury, the more the amount of mediators released and therefore could be a reflection of the severity of pain, swelling and trismus. The type of impaction gives a prediction of the difficulty of extraction and hence the severity of postoperative tissue reactions. Duration of surgery is an operative factor that has been found to influence the immediate postoperative factors following impacted third molar surgery ${ }^{8}$.Older patients had more trismus and dry socket. Longer duration of surgical extraction was associated with more swelling ${ }^{13}$.Patient should expect to find it difficult to open their mouth fully and eat comfortably even after one week. Some will experience a change in their ability to talk even at day $7^{14}$. In this study, we assess the immediate postoperative tissue reactions after surgical extraction of impacted mandibular third molar in different aged patient.

\section{Methods:}

The present prospective study was carried out in the Department of Oral \& Maxillofacial Surgery, BSMMU, Dhaka from January 2010 to December 2011. All the patients, undergone to surgical extraction due to impacted mesioangular third molar, who fulfilled the basic requirements of inclusion and exclusion criteria. 100 patients were included in this study ( 54 Female and 46 Male). All 
the patients were divided into three groups according to diagnosis and age. In group I Patients were selected between 18-25 years old, in group II 26-35 years old patients and group III 36-42 years old patients. The inclusion criteria- a)18-42years old patient.b) Mesioangular impaction of mandibular third molars.c)Patients showing cooperation with the study and with postoperative follow-up. And the exclusion criteria - a) Age: Below 18 years and above 42 years. (Prophylactic removal of third molar in orthognathic and orthodontic case). b) Grossly carious tooth. c) Diabetic, Cancer, Bleeding disorder. d) Pregnancy.

The Surgical Procedure each and every tooth extraction was done under loco-regional anesthesia in the same operating room with the same type of instruments under similar conditions. Sterile physiologic saline solution was used for irrigation and 3-0 silk suture was used to close the wound. All the parts of tooth were loosened with a dental elevator and were removed. Sutures were removed on 7 th post operatine deriod. Post operative instructions were given to each patients following extraction.Patients were asked to do the regular follow up on 2nd POD and 7th POD for evaluation of pain, swelling and maximum mouth opening.In addition to postoperative instructions and prescriptions for analgesics, patients received a standard visual analog scale (VAS) form to complete. The scale used in this study was a $10-\mathrm{cm}$ scale with no pain indicated on the left hand side and worst pain imaginable indicated on the right hand side. Patients were asked to mark along the scale where they felt their pain experience best corresponded ${ }^{15}$.

\begin{tabular}{|l|l|l|l|l|l|l|l|l|l|l|}
\hline 0 & 1 & 2 & 3 & 4 & 5 & 6 & 7 & 8 & 9 & 10 \\
\hline
\end{tabular}

No Pain

Unbearable Pain

Fig 1: Visual Analogue Scale consisting of $10 \mathrm{~cm}$ horizontal line.

Three measurements were made between five reference points: tragus, soft tissue pogonion, lateral corner of the eye, angle of the mandible, and outer corner of the mouth, preoperatively, and on the second and seventh postoperative days. The preoperative sum of the 3 measurements was considered as the baseline for that side. The difference between each postoperative measurement and the baseline indicated the facial swelling for that day ${ }^{16}$. Line A: The distance between lateral corner of the eye and angle of mandible, Line B: tragus and outer corner of the mouth, Line C: tragus and soft tissue pogonion (in chin) were measured preoperatively, 2nd POD and 7th POD.

The evaluations of facial swelling were carried out on 2nd POD and 7th POD.

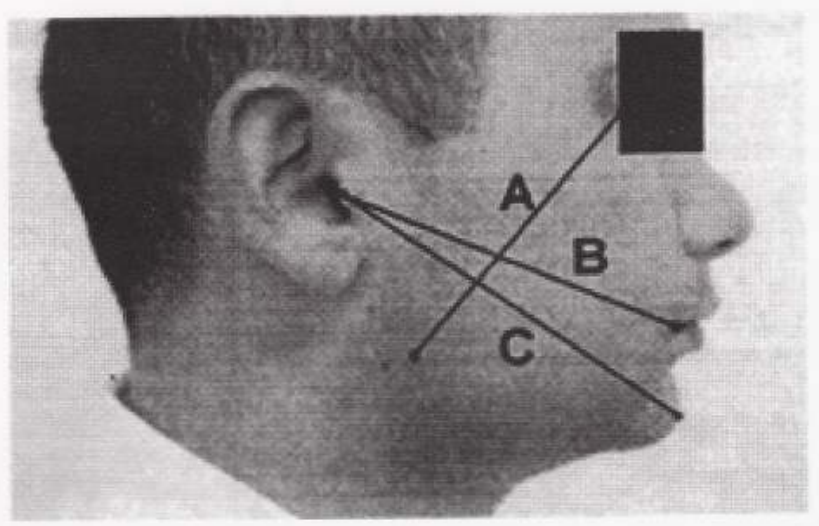

Fig-2: Tape measuring method for evaluation of facial swelling A: The distance between lateral corner of the eye and angle of mandible, B: tragus and outer corner of the mouth, C: tragus and soft tissue pogonion (in chin) were measured preoperatively, 2nd POD and 7thPOD.The mouth opening was measured before the surgical procedure and on 2nd POD, 7th POD with a vernier caliper, measuring scale/ruler or measuring tape from the incisal edge of the upper and lower right central incisors at maximum opening of the jaw.

The data were screened and checked for any missing values and discrepancy. Computer based statistical analysis was carried out with appropriate techniques and systems. Data were processed and analyzed using SPSS version 16.0 for windows. Both qualitative and quantitative tests were performed. For comparison between groups, Chi square (x2) test was performed for qualitative 
variables and student ' $\mathrm{t}$ ' test was performed for quantitative variables. The level of significance was set at 0.05 and $\mathrm{p}<0.05$ considered significant. The summarized data were interpreted accordingly and were then presented in the form of tables, graphs and bar diagrams.

\section{Result :}

In this prospective study a total 100 subjects were interviewed. Among the respondents $55.0 \%$ were aged between $18-25$ years, $38.0 \%$ were in $26-35$ age group and only $7.0 \%$ were within $36-42$ years of age. Regarding this age distribution all the respondents were divided between three groups as Group I (18-25 years), Group II (26-35 years) and group III (36-42 years) and MMO, swelling and level of pain were compared between these three groups. The mean age of all the respondents was $26.42+$ 5.503 years (Table 1$)$.

Table-I

Age distribution among the study respondents

\begin{tabular}{|c|c|c|c|c|}
\hline \multirow{2}{*}{$\begin{array}{l}\text { D em ographic } \\
\text { V arable }\end{array}$} & \multirow[b]{2}{*}{$\begin{array}{l}\text { Age } \\
\text { Grou ps }\end{array}$} & \multirow{2}{*}{$\begin{array}{l}\text { C ategory } \\
\text { In } Y \text { ears }\end{array}$} & \multicolumn{2}{|c|}{$\mathrm{Nu} \mathrm{m}$ ber ofPatients } \\
\hline & & & $\begin{array}{l}\text { Frequ ency } \\
(n=100)\end{array}$ & Percent \\
\hline \multirow[t]{3}{*}{ Age } & Group I & $18-25$ & 55 & 55.0 \\
\hline & Group II & $26-35$ & 38 & 38.0 \\
\hline & Group III & $36-42$ & 7 & 7.0 \\
\hline$M$ ean $\pm S D$ & & $26.42 \pm 5.503$ & & \\
\hline Range ( $\mathrm{m}$ in $-\mathrm{m}$ ax ) & & $(18-42)$ & & \\
\hline
\end{tabular}

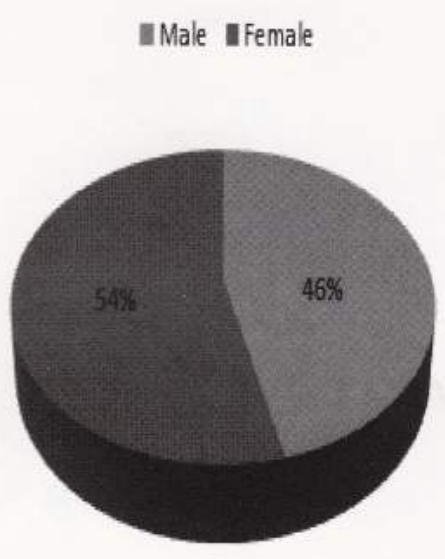

Fig-3: Pie diagram showing Sex distribution amongthe respondents $46.0 \%$ and $54.0 \%$ were male and female respectively.

Preoperatively the mean difference for maximum mouth opening between Group I and Group II was $4.162 \mathrm{~mm}$, which was also statistically highly significant $(\mathrm{P}<0.01)$. On 2nd POD mean difference was $0.008 \mathrm{~mm}$ and during 7th POD a high significance level $(\mathrm{P}<0.01)$ represents $3.672 \mathrm{~mm}$ as a significant difference between groups. Preoperatively and on 7th POD maximum mouth opening was more in Group II than in Group I. Between Group I and III preoperative difference were 2.878 which was also statistically significant $(\mathrm{P}<0.05)$, on 2 nd POD $0.745 \mathrm{~mm}$ and on 7th POD $2.909 \mathrm{~mm}$ though any of these differences did not show any statistical significance. And between group II and III preoperative difference was $1.289 \mathrm{~mm}$, on $2 \mathrm{nd}$ POD $0.737 \mathrm{~mm}$ and 7 th POD 0.763 $\mathrm{mm}$. So, there were no significant $(\mathrm{P}>0.05)$ differences revealed between older age groups (Table-II). 
Table-II

Maximum Mouth Opening (MMO) in Preoperative, 2nd POD and 7th POD.

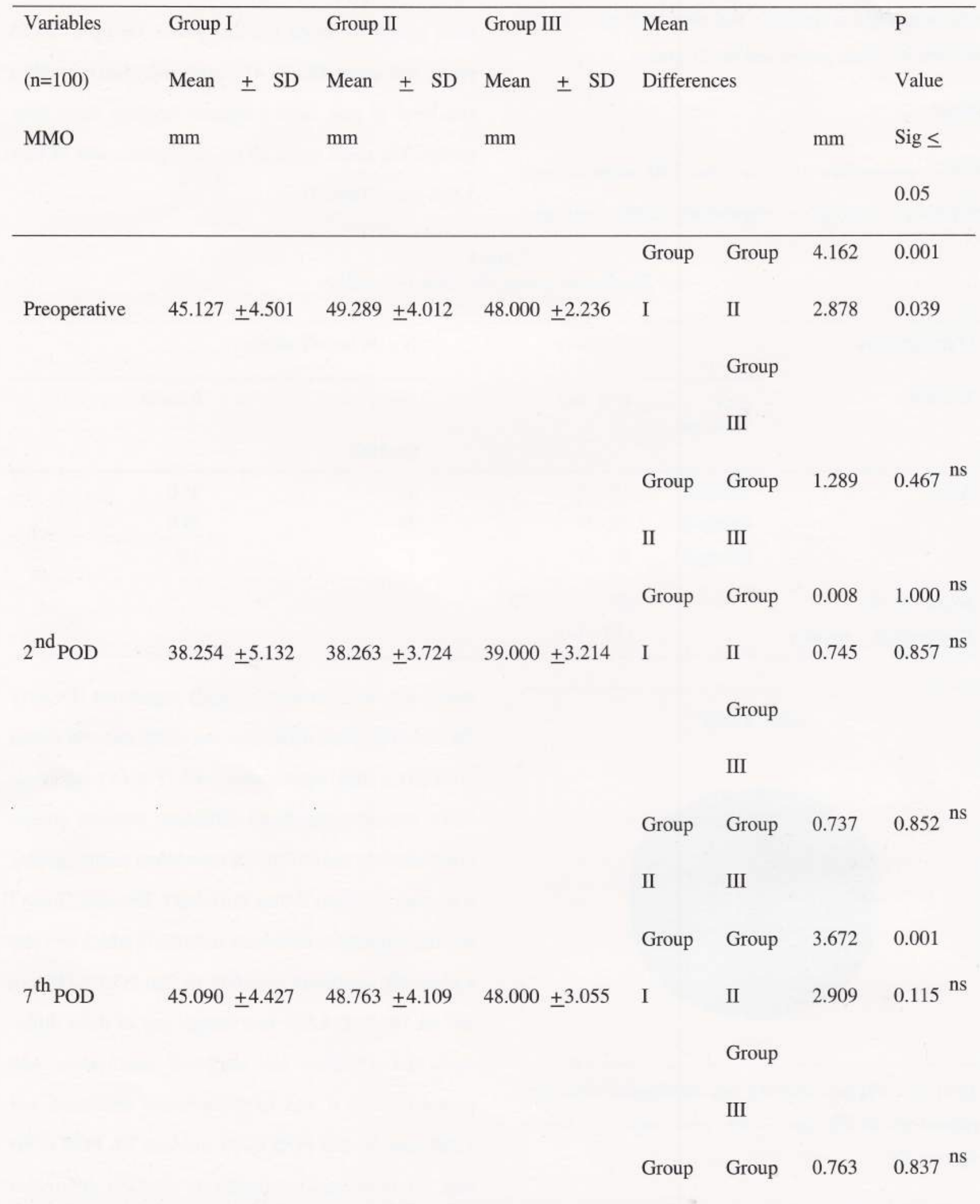

$\mathrm{ns}=$ Not Significant.Statistical analysis was done by Unpaired ' $\mathrm{t}$ ' test.Significant cutoff value $<0.05$ 
Among all respondents, in average Group I subjects showed $84.67 \%$ of their total mouth opening in the 2nd postoperative day, in comparison with $77.64 \%$ by the Group II and $81.14 \%$ of Group III. And during 7th POD all the groups represented around $99.00 \%$ of their total mouth opening (Fig: 4).

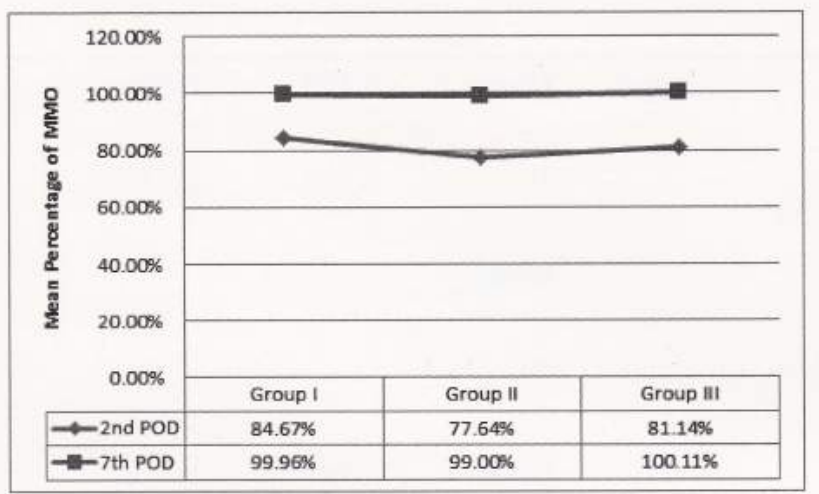

Fig-4: Comparison of mean percentage of mouth opening among three age groups in follow up visits

The number of patients having their Teeth in Position A and B, in Group I were $66.7 \%$ and $46.6 \%$ respectively and in Group II were $28.6 \%$, and $44.8 \%$ respectively. Only $4.8 \%$ of position A and $8.6 \%$ of position B belonged to Group III (Fig: 5).

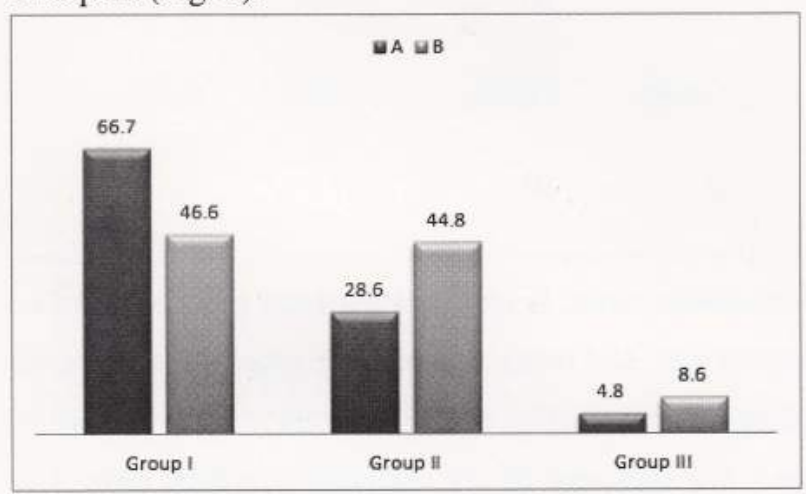

Fig-5: Distribution of respondents according to teeth position among three age groups

In average, Group I participants had $10.91 \mathrm{~mm}$ of swelling, in contrast with $23.71 \mathrm{~mm}$ and $25.71 \mathrm{~mm}$ among older age groups. And during 7th POD mean swelling of group I was only $0.29 \mathrm{~mm}$. So, younger patients represented rapid elimination of swelling than the seniors (Fig: $6)$.

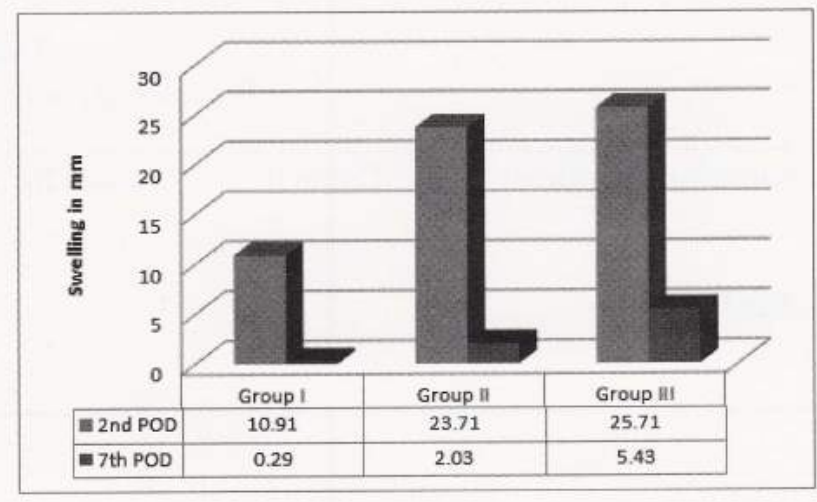

Fig-6: Comparison of swelling among three groups during 2nd and 7 th $P O D$

Regarding pain score severity of pain had been measured among all three groups and mean pain score of Group I was 3.527 with SD 1.015 and mean difference between Group I vs. II and Group I vs. III were highly significant $(\mathrm{P}<0.01)$. But Group II and III did not represent any significant $(\mathrm{P}>0.05)$ difference in mean pain score. And during 7th POD mean difference between Group I and II was only 0.685 but still very highly significant $(\mathrm{P}<0.01)$. Group I and III showed mean 1.478 level of difference in pain score, Group II and III demonstrated 0.793 of highly significant $(\mathrm{P}<0.01)$ difference (Table 4$)$.

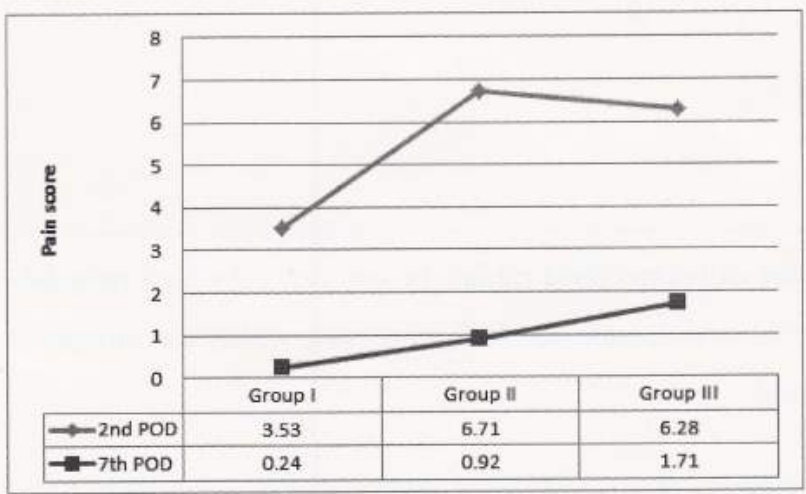

Fig-7: Showing level of pain in average during the follow up visits

\section{Discussion :}

There was significant relationship in distribution of sex in impaction. It was observe that the distribution of impacted third molars by sex is shown in figure I; there were significantly more females $(56 \%)$ than males $(44 \%)$ with at least 
Table-III

Presence of pain regarding age groups

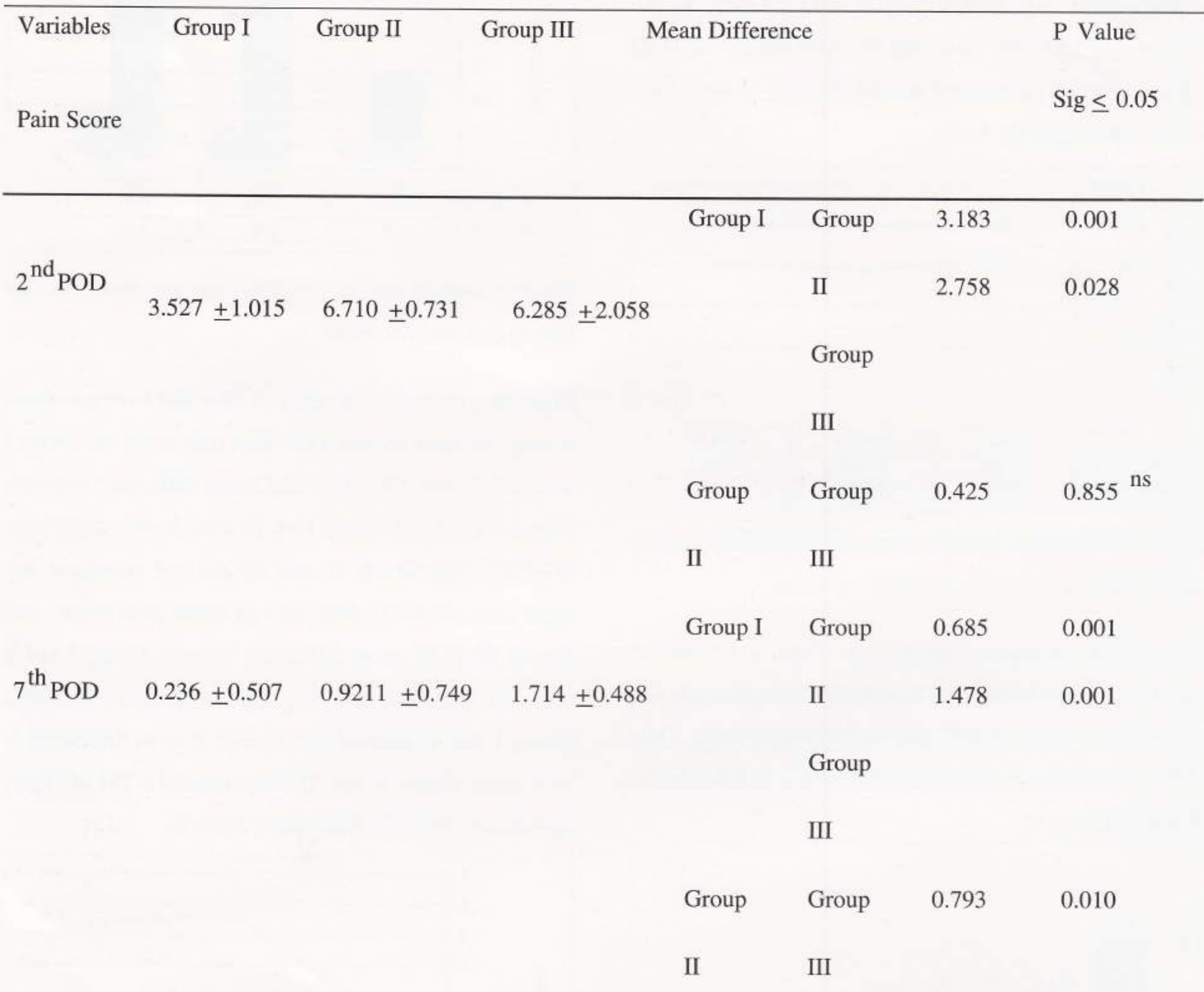

one impacted third molar. In our study $54 \%$ of respondents were female and $46 \%$ were male which was similar to that.

Surgical removal of third molars causes significant pain, swelling, and trismus even when teeth are removed using a gentle surgical technique ${ }^{17}$.

In our study total 100 patients with mesioangular impaction were investigated. All the patients were categorized into three age groups, Group I (18-25 years), Group II (26-35 years) and Group III (36-42 years). It was stated that, older age was found to increase the risk of an extended operation time ${ }^{4}$. The patient's age when the mandibular molar is removed has been reported to be of importance, and many studies have related postoperative complications to older age. The patient's age was found to be a risk indicator for an extended operation time. The older age groups had more than 2 times higher risk of an extended operation time compared with youngest age group. Older age was found to increase the risk of an extended operation time. It was observe that the every minute increase in operating time there was a $9 \%$ increase in chance of experiencing pain (VAS $>1)^{5}$. In our study group III experienced more pain in $2^{\text {nd }} \mathrm{POD}(6.285+2.058)$ and in $7^{\text {th }}$ POD $(1.714+0.488)$ than Group I $(3.527+1.015$ in $2^{\text {nd }}$ POD and $0.236+0.507$ in $7^{\text {th }}$ POD) and Group II 
in $7^{\text {th }}$ POD) and Group II $(6.710+0.731$ in 2 nd POD and $0.9211+0.749$ in $7^{\text {th }}$ POD) . The longer the duration of tissue injury, the more the amount of mediators released and therefore could be a reflection of the severity of pain, swelling and trismus ${ }^{6}$.The patients in the age range of 35-42 years recorded a significantly lower pain score $(\mathrm{p}=0.5)$ compared with lower age groups on day 1 , but subsequently the pain recorded was significantly higher than that recorded for the lower age groups $(\mathrm{p}=0.01,0.2$ on day 3 and 4 respectively) which also corresponds to our study. Age is commonly cited as a risk factor for post extraction complications and age was found to be significantly associated with complications. In addition to change in bone density, increased age is associated with complete root formation and diminished wound healing capacities, which can result in higher operative and inflammatory complications ${ }^{7}$. Subjects over age 25 would be statistically significantly more likely to experience complications after third molar surgery compared with those under age $25^{8}$. Female and adult patients (age $>25$ years) should be informed before third molar surgery about the likelihood of requiring more time for improvements in oral function, lifestyle, and pain recovery compared with male and younger patients (age $<21$ years) following third molar surgery.

Each and every tooth extraction was done under locoregional anaesthesia in the same operating room with the same type of instruments. All the patients were free of pain and other inflammatory conditions like swelling, hyperemia and trismus at the time of surgery. Immediately before tooth extraction all patients were asked to rinse the mouth for 1 minute with a $0.12 \%$ chlorhexidine mouthwash. The technique was standardized for tooth extraction. Extraction was performed with buccal guttering technique after adequate elevation and reflection of full thickness buccalmucoperiosteal flap.

The older patients suffer more this could be due to the delayed healing capacities associated with aging as well as the increased bone density that might make the surgery more difficult. Longer duration of the surgical extraction was associated with more swelling ${ }^{13}$. The Facial swelling is affected by individual characteristics such as age and $\operatorname{sex}^{10}$. Swelling was more common in patients over 40 years of age; pain did not vary with age. In our study in average, Group I participants had $10.91 \mathrm{~mm}$ of swelling, in contrast with $23.71 \mathrm{~mm}$ and $25.71 \mathrm{~mm}$ among older age groups. And during 7th POD mean swelling of group I was only $0.29 \mathrm{~mm}$. So, younger patients represented rapid elimination of swelling than the Group II and Group III which showed similarity.

Patient's age was found to be a risk factor only for severe trismus ; that is , patient's age $<22.0$ years were found to have a lower risk than older patients ${ }^{2}$. Older patients are at greater risk of severe trismus after third molar surgery. The patients above 35 years recorded more swelling and trismus. That study recorded a significant influence of age on postoperative morbidity following surgical extraction of impacted third molar teeth. A higher degree of trismus and facial swelling was recorded in patients with advancing age. In our study the mean difference for Maximum Mouth Opening between Group I and Group II on 2nd POD mean difference was $0.008 \mathrm{~mm}$ and during $7^{\text {th }}$ POD a high significance level $(\mathrm{P}<0.01)$ represents $3.672 \mathrm{~mm}$ as a significant difference between groups. Preoperatively and on $7^{\text {th }}$ POD Maximum Mouth Opening was more in Group II than in Group I. Between Group I and III preoperative difference were 2.878 which was also statistically significant $(\mathrm{P}<0.05)$, on $2 \mathrm{nd} \mathrm{POD} 0.745 \mathrm{~mm}$ and on $7^{\text {th }}$ POD $2.909 \mathrm{~mm}$ though any of these differences did not show any statistical significance. And between group II and III preoperative difference was $1.289 \mathrm{~mm}$, on $2 \mathrm{nd}$ POD $0.737 \mathrm{~mm}$ and $7^{\text {th }}$ POD $0.763 \mathrm{~mm}$. So, there were no significant $(\mathrm{P}>0.05)$ differences revealed between older age groups. (Table II.)

The postoperative seventh day, all symptoms had restored to the preoperative level in both groups, which is almost parallel to our study ${ }^{18}$.Some authors believe that all impacted third molars should be removed even if no symptoms are observed, with the purpose being to minimize the risk of disease associated with these teeth ${ }^{19}$. 


\section{Conclusion:}

After assessment of results of the study the rate of postoperative morbidity (pain, trismus and swelling) and the risks of permanent sequelae increase with age. Therefore, it is recommended that, once a decision has been made to extract an impacted third molar, the surgery should be carried out as soon as possible and well before the age of 25 years. The knowledge of the effect of age on postoperative inflammatory reactions following third molar surgery is very important because it will assist in treatment planning. It could be used as an objective tool to educate patients on the need for early extraction of an impacted third molar to minimize postoperative morbidity. All 18-20 years aged young should be screened radio logically and clinically to find out impacted tooth. Once a decision has been made to extract an impacted third molar, the surgery should be carried out as soon as possible and well before the age of 25 years.

\section{References :}

1. QuekSL,Tay CK, Toh SL, Lim KC. Pattern of third molar impaction in a Singapore Chinese population: a retrospective radiographic survey. Int J Oral Maxillofac Surg.2003; 32: 548-552.

2. Siddiqui A, Morkel JA, Zafar S. Antibiotic prophylaxis in third molar surgery: A randomized double-blind placebo-controlled clinical trial using split-mouth technique. Int J Oral Maxillofac Surg. 2010; 39: 107-114.

3. Cerqueira PRF, Vasconcelos BCE, Nogueira RVB.Comparative study of the effect of a tube drain in impacted lower third molar surgery.J. Oral Maxillofac Surg. 2004; 62:57-61.

4. Grossi GB, Mariorana C, Garramone RA, BorgonovoA, Santoro F.Assessing postoperative discomfort after third molar surgery: A prospective study.J Oral Maxillofac Surg.2007; 65: 901-917.

5. Beeman CS. Third molar management: a case for routine removal in adolescent and young adult orthodontic patients. J Oral Maxillofac Surg.1999; 57:824-830.

6. BenediktsdottirIS, Wenzel A, Petersen JK ,Hintze H. Mandibular Third molar removal: Risk indicators for extended operation time, postoperative pain,andcomplications.OralSurg Oral Med Oral Patho Oral Radiol Endod.2004; 97:438-446.
7. Baqain ZH, Karaky AA, Sawair F , Khaisat A, RajabLD Frequency estimates and risk factors for postoperative morbidity after third molar removal: A prospective cohort study.J Oral maxillofacSurg.2008; 66: 2276-2283.

8. Bello S, Adeyemo W, Bamgbose B, Obi E ,Adeyinka A. Effect of age , impaction types and operative time on inflammatory tissue reactions following lower third molar surgery,Head\& face med.2011; 7: 1-8

9. Bui $\mathrm{CH}$, Seldin EB, Dodson TB.Types, frequencies, and risk factors for complictions after third molar extraction. J Ora Maxillofac Surg.2003; 61: 1379-1389.

10. ChuangSK ,Perrott DH, SusarlaSM ,DodsonTB.Age as a risk factor for third molar surgery complications.J Oral Maxillofac Surg.2007; 65:1685-1692.

11. GbotolorunOM, ArotibaGT ,LadeindeAL.Assessment of Factors Associated With Surgical Difficulty in Impacted Mandibular Third Molar Extraction.J Oral MaxillofacSurg.2007; 65: 1977-1983.

12. Yuasa $\mathrm{H}$, Sugiura M. Clinical postoperative findings after removal of impacted mandibular third molars:prediction of postoperative facial swelling and pain based on preoperative variables. $\mathrm{Br}$ journal of Oral and Maxillofacial Surg.2004; 42: 209-214.

13. MalkawiZ,Al-Omiri MK, KhraisatA. Risk indicators of postoperative complications following surgical extraction of lower third molars. Med Princ Pract.2011; 20: 321-325.

14. Savin J, Ogden GR. Third molar surgery-a preliminary report on aspects affecting quality of life in the early postoperative period.Br J Oral Maxillofac Surg. 1997;35: 246-253.

15. Kirk DG, ListonPN, Tong DC, Love RM. Influence of two different flap designs on incidence of pain,swelling,trismus, and alveolar osteitis in the week following third molar surgery.Oral Surg Oral Med Oral Pathol Oral Radiol Endod.2007; 104: 1-6.

16. Ustun Y, Erdogan O, Esen E ,Karsli ED. Comparison of the effects of two doses of methylprednisolone on pain, swelling, and trismus after third molar surgery.Oral Surg Oral Med Oral Pathol Oral Radiol Endod.2003; 96: 535-539.

17. Buyukkurt MC, GungormusM, Kaya O.The effect of single dose of prednisolone with or without diclofenac on pain, trismus and swelling after removal mandibular third molars.J Oral Maxillofac Surg. 2006; 64: 1761-1766.

18. Bamgbose BO, Akinwande JA, Adeyemo WL, Ladeinde AL, ArotibaGT ,Ogunlewe MO. Effects of co-administered dexamethasone and diclofenac potassium on pain, swelling and trismus following third molar surgery. Head Face Med.2005; 1: 1 - 6 .

19. Stathopoulos P,MezitisM ,TitsinidesS, StylogianniE. Cyst and tumours associated with impacted third molars:is prophylactic removal justified? J Oral Maxillofac Surg. 2011; 69: 405-408. 